\title{
Management of Intermittent Exotropia in Children
}

Ahmed Salah Abdel-Rehim ${ }^{1}$, Abdul-Mongy Elsayed Ali', Alaa Abdul-Mongy Abdul-Fattah Sadaka ${ }^{2}$, Dina Hamdy Mohamed Mohamed ${ }^{* 1}$

${ }^{1}$ Departments of Ophthalmology, Faculty of Medicine, Al-Azhar University,

${ }^{2}$ Departments of Ophthalmology, Faculty of Medicine, Aswan University, Egypt

*Corresponding author: Dina Hamdy Mohamed Mohamed, Mobile: $( \pm 20) 01148728477$

\begin{abstract}
Background: Intermittent exotropia (IXT) is a common form of childhood exotropia, accounting for about 50-90\% of all the exotropia and affecting about $1 \%$ of the general population.

Objective: The purpose of this study was to evaluate difference modalities for treatment of intermittent exotropia either by non-surgical and surgical methods. Patients and Methods: this study included 40 patients of both sexes with exodeviation divided into 2 groups; Group (A): 20 patients subjected to non-surgical treatment and Group (B): 20 patients underwent surgical treatment; bilateral lateral rectus recession (BLR).

Results: In non-surgical group the success rate was 55\% after 12 months of treatment. Overminus glasses are more effective in control of IXT than part-time occlusion (PTO) and convergence exercise. The success rate was $86 \%$. While the success rate in PTO was $43 \%$ and the success rate of convergence exercise was $33 \%$. Poor compliance in PTO and convergence exercise therapy affect the treatment effectiveness. In surgical group (BLR) the success rate was $75 \%$. Under-correction was $20 \%$ and the overcorrection was $5 \%$. No complications were found. No lateral incomitance was observed. Conclusion: Surgical method is more effective in treatment of IXT than non-surgical methods, but the non-surgical method is more important in younger children. The over-minus glasses is more effective in treatment of IXT than the other non-surgical method due to poor compliance among children in PTO and Convergence exercise therapy. A larger trial for a longer duration is warranted to assess the effectiveness of different modalities of treatment of IXT.
\end{abstract}

Keywords: Intermittent exotropia, children, IXT

\section{INTRODUCTION}

Intermittent exotropia is the most frequent form of divergent strabismus (1). It is characterized by fluctuations in the visual sensory system involving binocular vision with stereopsis when the eyes are aligned and suppression with abnormal retinal correspondence when the deviation occurs ${ }^{(2)}$.

Intermittent exotropia can be further classified into three types based on the difference between the distance and near deviations: (1) basic, where the distance and near deviations are similar within 10 prism diopters (PD) and the target angle is the distance deviation ${ }^{(3)}$. (2) divergence excess (pseudo and true), where the exotropia is larger for distance fixation than near fixation ( $\geq 10 \mathrm{PD})$. True divergence prolonged binocular dissociation by monocular patching (i.e., Patch test). Pseudo-divergence excess is when the near deviation increases after the patch test, so the distance and near deviation are similar (3) convergence insufficiency when the near deviation is more than 10 PD larger than the distance deviation ${ }^{(4)}$ if there is no significant distance deviation, with an exodeviation for near, then this is a pure convergence insufficiency. It is more common in teenagers who report asthenopia ${ }^{(3)}$.

Both non-surgical and surgical management techniques may be used, the latter being recommended for poorly controlled or symptomatic exotropia ${ }^{(5)}$.

In general, there are many methods for nonsurgical treatment for intermitted exotropia .One method is to prescribe 2 to 3 diopters of myopic correction over what is required by cycloplegic refraction. Overminusing induces accommodative convergence, thus reducing the exodeviation. Another method is part-time monocular occlusion therapy. By occluding the dominant eye, the patient is forced to use the non-preferred eye, thus providing ant suppression therapy. Part-time occlusion therapy may be tried in younger patients as a method for delaying surgery, but it is only a temporary measure. Convergence exercise are useful for convergence insufficiency but for most cases of intermittent exotropia. the use of antisuppression orthoptic therapy and diplopia awareness are not indicated, as this practice to the patient ${ }^{(\boldsymbol{(})}$.

Surgery is thought to be an effective method for the treatment of intermittent exotropia. Popular intervention criteria include a reduction in or loss of stereoacuity (at near or distance), deteriorating fusional control, a large angle of deviation, or a combination; but potential thresholds remain poorly defined ${ }^{(7)}$.

The goals of the surgery for intermittent exotropia are to restore alignment and preserve or restore binocular function. However, the optimal time for surgical intervention remains unclear. The critical point is the postoperative stereoacuity establishment. Most surgeons believe that early surgery for children is indicated to prevent progression to constant exotropia and restoration of bifixation, whereas in most adult patients surgery can only help to achieve orthotropia, but not bifoveal fixation ${ }^{(8)}$.

The purpose of this study was to evaluate difference modalities for treatment of intermittent exotropia either by non-surgical and surgical methods. 


\section{PATIENTS AND METHODS}

This prospective study included a total of 40 patients of both sexes with exodeviation attending at Al-Azhar and 1Aswan University Hospitals. Approval of the ethical committee and a written informed consent from all the parents of the subjects were obtained.

Patients underwent surgical and non-surgical modalities for treatment then complete follow-up for 12 months was done. Patients were divided into two groups; Group (A): 20 patients subjected to nonsurgical treatment and Group (B): 20 patients underwent surgical treatment; bilateral lateral rectus recession (BLR).

\section{Inclusion Criteria:}

- Age 4 to 15 years.

- No previous intraocular surgery, strabismus surgery, or botulinum toxin treatment.

\section{Exclusion Criteria}

- Oblique muscle dysfunction.

- Limitation of ocular rotations due to restrictive or paretic strabismus.

- Prior strabismus surgery or botulinum toxin injection.

- Significant neurological impairment such as cerebral palsy.

All patients in the study underwent comprehensive ophthalmic examination including:

1. History taking.

2. Complete ophthalmological examination:

A. Visual acuity.

B. Refraction.

C. Extra ocular muscles examination.

D. Measure angle of deviation at distance and near vision with and without correction.

E. anterior segment and posterior segment examination

\section{Enrollment Testing}

At the enrollment visit, control of the exodeviation was assessed at distance $(6 \mathrm{~m})$ and near $(1 / 3 \mathrm{~m})$.After an initial control assessment, magnitude of exodeviation was assessed at distance $(6 \mathrm{~m})$ whenever possible and near $(1 / 3 \mathrm{~m})$ using the PACT with cooperative children and photos were taken before the start of treatment for almost all children in the study after the consent of the parents. Monocular distance BCVA was measured using Snellen acuity chart for cooperative older children.

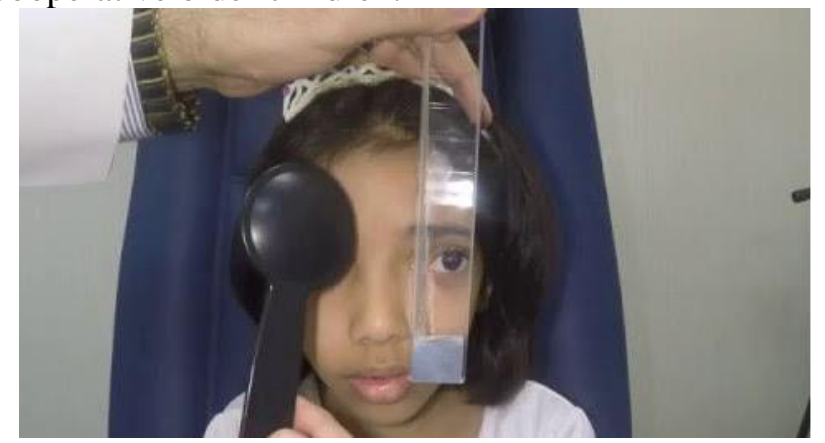

Figure (1): shows measurement angle of deviation by PACT.

\section{Group A: (Nonsurgical)}

\section{1- Convergence exercise:}

Participants assigned to the Convergence exercise. The treatment regimen for convergence exercise by Pencil-Push Test by Keeping a pen or pencil at arms length in the line of vision between the two eyes. Slowly bring the pencil towards the nose. Focus should be on the tip of the pencil. As you bring the pencil closer, the image becomes double at one point. Stop at this point and again take the pencil away to arms length.

\section{2- Overminus glasses}

Participants assigned to the overminus spectacle group were prescribed spectacles with $-1.00 \mathrm{D}$ added to the sphere power of the cycloplegic refraction.

3- Part-time occlusion therapy (PTO):

The treatment regimen for PTO was to cover the eyes alternately or unilateral for the dominant eye for 4 hours whether continuous or separated daily for 12 months and guaranteed that the patch was completely closing the eyes so the child could not see through it.

Group B: Surgical (BLR):

a) Twenty Participants were operated upon under general anesthesia.

b) Sterilization of instruments, disinfection and toweling of the eyes using betadine 5\% and sterilized opside respectively.

c) A limbal incision to expose the LR was done; first by grasping the limbal conjunctiva using a toothed forceps retracting the globe then making a radial wing incision and extending it to the fornix. Second, performing a limbal peritomy right on the limbus in front of the muscle. Third, making the second radial wing incision above the muscle.

d) Hooking the rectus muscle: a toothed forceps was used to grasp the conjunctiva at the fornix, to retract the eye and expose the scleral quadrant between the muscles.

e) Muscle dissection was performed with blunt, curved Westcott scissors. Once on stretch using toothed forceps.

f) Exposure of the whole length of the LR using a second hook

g) Muscle Suturing: using three-point fixation. A "large" $3 \mathrm{~mm}$ central security knot full thickness, in the center of the muscle, tied in a square knot. Then one partial thickness and another one full thickness locking bites are placed at each edge of the muscle using 6/0 vicryl.

h) Disinserting the muscle from its insertion

i) The muscle is reattached to its insertion via hang back technique

j) Limbal incision is closed using virgin silk $8 / 0$ Follow up visits:

Patients were followed up at 3,6 and 12 months of treatment. In each visit, we stressed on assessment of angle deviation for near and far with and without glasses, and taking pictures after the treatment to be 
compared with before the treatment. The participant's parents were asked also to notice the home control of the deviation and give it a percentage with most of the time (poor control) or half of the time (moderate) or less than half of the time (good control).

\section{Statistical analysis:}

Recorded data were analyzed using the statistical package for social sciences, version 20.0 (SPSS Inc., Chicago, Illinois, USA). Quantitative data were expressed as mean \pm standard deviation (SD). Qualitative data were expressed as frequency and percentage.

The following tests were done:
Independent-samples t-test of significance was used when comparing between two means.

Chi-square $\left(\mathrm{x}^{2}\right)$ test of significance was used in order to compare proportions between two qualitative parameters.

- The confidence interval was set to $95 \%$ and the margin of error accepted was set to $5 \%$. The p-value was considered significant as the following:

Probability (P-value)

- P-value $<0.05$ was considered significant.

- P-value $<0.001$ was considered as highly significant.

- P-value >0.05 was considered insignificant.

\section{RESULTS}

Table (1): Demographic data of the two studied groups regarding.

\begin{tabular}{|c|c|c|c|c|c|}
\hline \multicolumn{2}{|c|}{ Demographic variable } & $\begin{array}{c}\text { Group A } \\
\text { (Non surgical) } \\
\end{array}$ & $\begin{array}{c}\text { Group B } \\
\text { (Surgical) }\end{array}$ & $\begin{array}{c}\text { Unpaired - t- } \\
\text { test }\end{array}$ & $P$ value \\
\hline \multirow{2}{*}{ Age (years) } & Mean \pm SD & $6.85 \pm 2.46$ & $9.5 \pm 3.69$ & \multirow{2}{*}{2.673} & \multirow{2}{*}{$0.012 *$} \\
\hline & Range & $4-12$ & $5-15$ & & \\
\hline \multirow{3}{*}{$\begin{array}{c}\text { Gender No. } \\
(\%)\end{array}$} & Female & $12(60 \%)$ & $12(60 \%)$ & \multirow{3}{*}{--} & \multirow{3}{*}{1.00} \\
\hline & Male & $8(40 \%)$ & $8(40 \%)$ & & \\
\hline & Total & 20 & 20 & & \\
\hline
\end{tabular}

*Significant

Table (1): shows age and gender of both groups. Mean age in group A is $(6.85 \pm 2.46)$. Its range is $4-12$ years. However, in group B mean age is $(9.5 \pm 3.69)$ and range is $5-15$ years. Significant statistical difference is detected between two groups as regards age.

Table (2): Convergence Exercise

\begin{tabular}{|c|c|c|c|c|c|c|c|c|}
\hline \multicolumn{3}{|c|}{ Convergence Exercise } & $\begin{array}{l}\text { Pre- } \\
\text { treatment }\end{array}$ & $\begin{array}{l}\text { After } \\
3 \text { months }\end{array}$ & $\begin{array}{l}\text { After } \\
6 \text { months }\end{array}$ & $\begin{array}{c}\text { After } \\
\text { nonths }\end{array}$ & $\begin{array}{l}\text { Wilcoxon } \\
\text { ranks test }(z)\end{array}$ & P value \\
\hline \multirow{5}{*}{ ¿̈ } & \multirow{2}{*}{$\frac{\stackrel{0}{00}}{E}$} & Mean \pm SD & $\begin{array}{c}26.83 \pm \\
8.50\end{array}$ & $\begin{array}{c}20.00 \pm \\
6.32\end{array}$ & $\begin{array}{c}15.83 \pm \\
6.65\end{array}$ & $\begin{array}{c}15.00 \pm \\
6.32 \\
\end{array}$ & \multirow[t]{2}{*}{2.226} & \multirow[t]{2}{*}{ p.032* } \\
\hline & & Range & $16-40$ & $10-25$ & $5-20$ & $5-20$ & & \\
\hline & \multirow{3}{*}{ 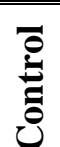 } & Poor & 1 & 1 & 0 & 0 & \multirow{3}{*}{1.732} & \multirow{3}{*}{1.00} \\
\hline & & Fair & 3 & 3 & 2 & 2 & & \\
\hline & & Good & 2 & 2 & 4 & \begin{tabular}{|l|l|}
4 \\
\end{tabular} & & \\
\hline \multirow{5}{*}{ تَ } & \multirow{2}{*}{$\begin{array}{l}\frac{0}{00} \\
\dot{Z}\end{array}$} & Mean \pm SD & $20.20 \pm 6.94$ & $5.00 \pm 7.07$ & $13.33 \pm 7.53$ & $\begin{array}{l}11.70 \pm \\
6.83\end{array}$ & \multirow[t]{2}{*}{2.264} & \multirow[t]{2}{*}{0.21} \\
\hline & & Range & $10-30$ & $5-25$ & $5-25$ & $5-20$ & & \\
\hline & \multirow{3}{*}{ 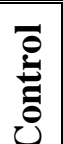 } & Poor & $\begin{array}{l}1 \\
\end{array}$ & 11 & $\begin{array}{l}0 \\
\end{array}$ & $\begin{array}{l}0 \\
\end{array}$ & \multirow{3}{*}{2} & \multirow{3}{*}{1.00} \\
\hline & & Fair & 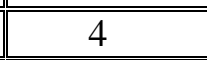 & $\overline{4}$ & 2 & 2 & & \\
\hline & & Good & 1 & 1 & 4 & 4 & & \\
\hline
\end{tabular}

*significant

Table (2): shows the comparison between near and far angle pretreatment and after 3, 6 and 12 months of treatment. First for near angle, pretreatment mean angle was (26.83 \pm 8.50). However after 3months of treatment mean angle

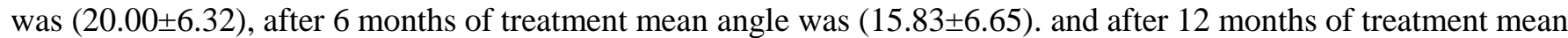
was (15.00 \pm 6.32$)$. Significant statistical in near angle after convergence exercise therapy. For far angle, pretreatment

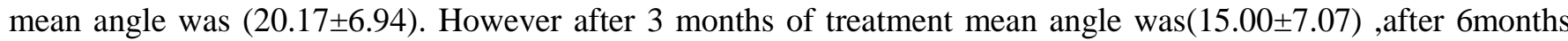
mean was $(13.33 \pm 7.53)$ and after 12 months of treatment mean was $(10.83 \pm 8.01)$. No significant statistical in far angle after convergence exercise therapy. 


\section{Example}

A seven year-old child with cycloplegic refraction \pm 1.75 DS in each eye and bilateral normal fundi, the angle was measured in the first visit before the start of convergence excesses treatment and in the follow up visits as shown in the figures below:
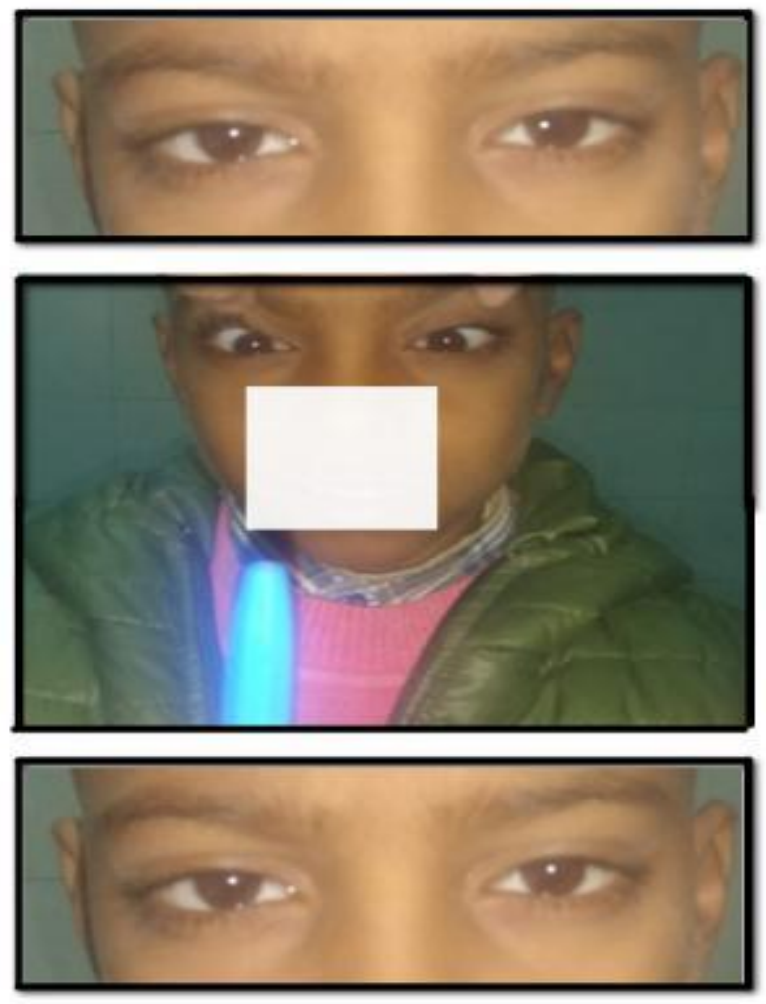

Figure (2): Shows Nsc 30 PD with fair control and Dsc 20 PD with good control. Figure (3): Shows Pencil-Push Test.

Figure (4): Shows orthophoric for near and far with good control after 12 months.

\section{Table (3): Overminus:}

\begin{tabular}{|c|c|c|c|c|c|c|c|c|}
\hline & & Overminus & $\begin{array}{c}\text { Pre- } \\
\text { tratment }\end{array}$ & $\begin{array}{l}\text { After 3 } \\
\text { months }\end{array}$ & $\begin{array}{l}\text { After 6 } \\
\text { months }\end{array}$ & $\begin{array}{r}\text { After 12 } \\
\text { months }\end{array}$ & \begin{tabular}{|c|} 
Wilcoxon \\
anks test (z) \\
\end{tabular} & $\mid P$ value \\
\hline \multirow{5}{*}{ 离 } & \multirow{2}{*}{$\frac{0}{200}$} & Mean \pm SD & $\begin{array}{c}21.29 \pm \\
7.06\end{array}$ & $\begin{array}{l}8.57 \pm \\
9.45\end{array}$ & $\begin{array}{c}4.29 \pm \\
7.87\end{array}$ & $\begin{array}{c}2.14 \pm \\
5.67\end{array}$ & \multirow[t]{2}{*}{2.384} & \multirow[t]{2}{*}{$<0.001 *$} \\
\hline & & Range & $14-30$ & $0-25$ & $0-20$ & $0-15$ & & \\
\hline & \multirow{3}{*}{ 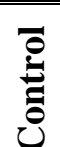 } & Poor & 1 & 1 & 0 & 0 & \multirow{3}{*}{2} & \multirow{3}{*}{$0.046^{*}$} \\
\hline & & Fair & 3 & 3 & 1 & 1 & & \\
\hline & & Good & 3 & 3 & 6 & 6 & & \\
\hline \multirow{5}{*}{ 䒕 } & \multirow{2}{*}{$\frac{0}{200}$} & Mean \pm SD & $\begin{array}{c}21.29 \pm \\
7.06 \\
\end{array}$ & $\begin{array}{c}8.57 \pm \\
9.45 \\
\end{array}$ & $\begin{array}{c}4.29 \pm \\
7.87 \\
\end{array}$ & $\begin{array}{c}2.14 \pm \\
5.67 \\
\end{array}$ & \multirow[t]{2}{*}{2.384} & \multirow[t]{2}{*}{$<0.001 *$} \\
\hline & & Range & $14-30$ & $0-25$ & $0-20$ & $0-15$ & & \\
\hline & \multirow{3}{*}{ 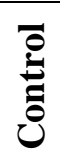 } & Poor & $\begin{array}{l}1 \\
\end{array}$ & 1 & 0 & 0 & \multirow{3}{*}{2} & \multirow{3}{*}{$0.046^{*}$} \\
\hline & & Fair & 3 & 3 & 11 & 11 & & \\
\hline & & Good & 3 & 3 & 6 & 6 & & \\
\hline
\end{tabular}

*significant

Table (3): shows the comparison between near and far angle pretreatment and after 3, 6 and 12 months of treatment. First for near angle , pretreatment mean angle was (21.29 \pm 7.06). However after 3months of treatment mean angle was $(8.57 \pm 9.45)$, after 6 months of treatment mean angle was $(4.29 \pm 7.87)$. and after 12 months of treatment mean was (2.14 \pm 5.67$)$. For far angle, pretreatment mean angle was (21.29 \pm 7.06$)$. However after 3 months of treatment mean angle was $(8.57 \pm 9.45)$, after 6 months of treatment mean angle was $(4.29 \pm 7.87)$. and after 12 months of treatment mean was $(2.14 \pm 5.67)$. There is significant in near and far angle after overminus therapy. 


\section{Example:}

A five year old child with cycloplegic refraction :OD: -1.00/-2.00 Axis10, OS: -1.00/-1.50 Axis180 and (IXT) with fair control was treated with overminus glasses and angle was measured before,during and after treatment and pictures as below.
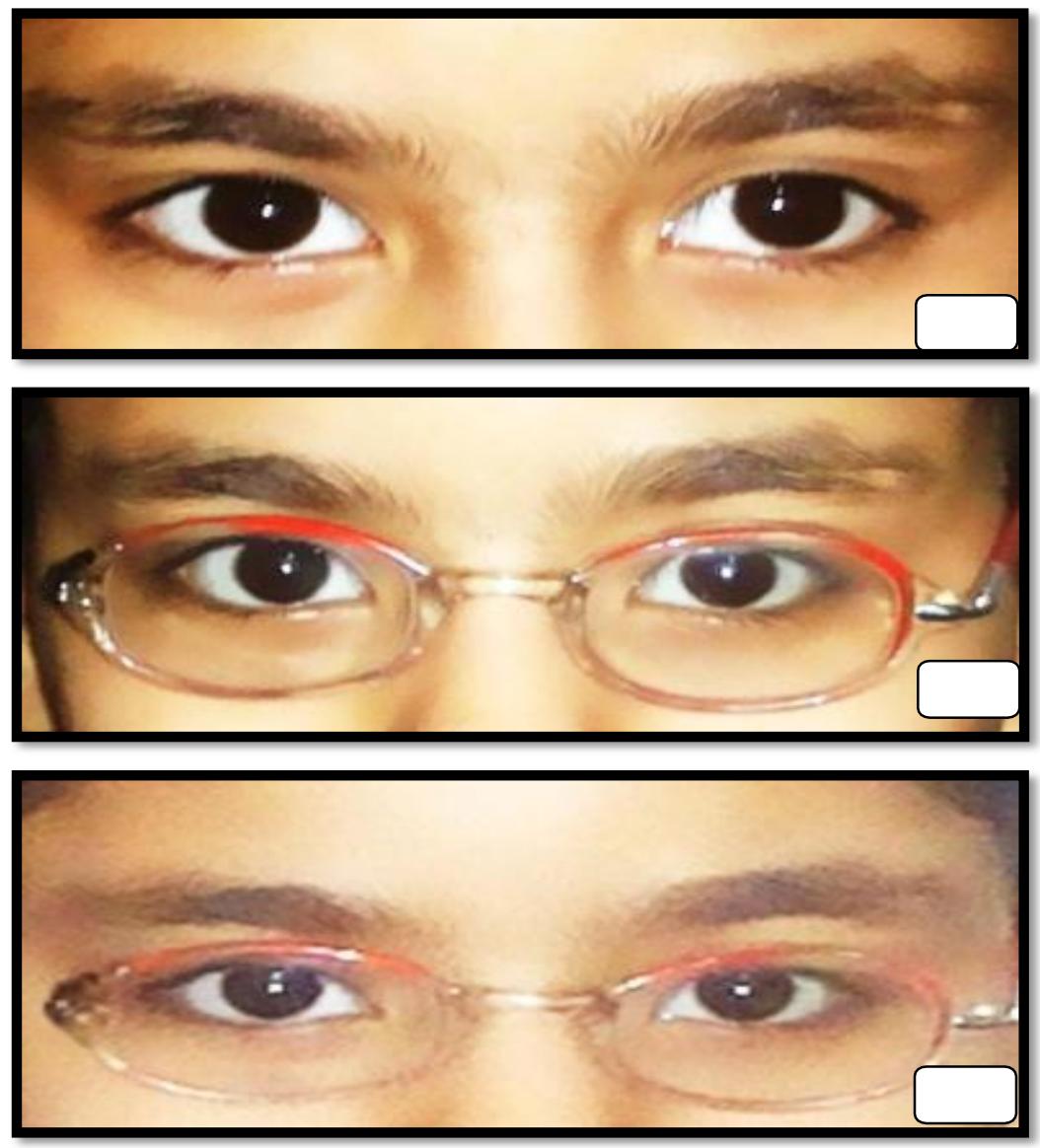

Figure (5): shows Nsc 25 PD with fair control ,Dsc 20 PD with fair control

Figure (6): shows orthophoric for near and far with good control after 6 months.

Figure (7): shows orthophoric for near and far with good control after 12 months.

Table (4): PTO.

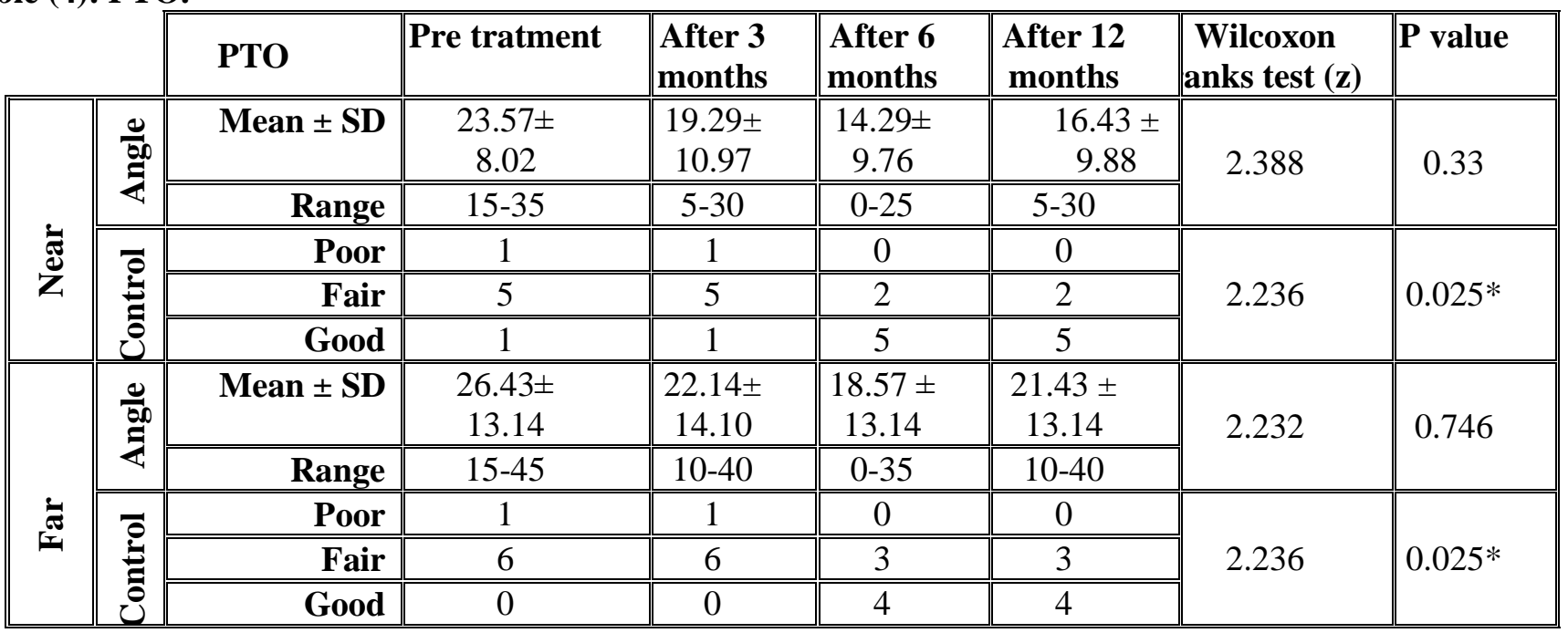

*significant

Table (4): shows the comparison between near and far angle pretreatment and after 3, 6 and 12 months of treatment. First for near angle, pretreatment mean angle was $(23.57 \pm 8.02)$. However, after 3 months of treatment mean angle

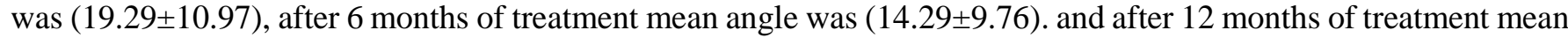

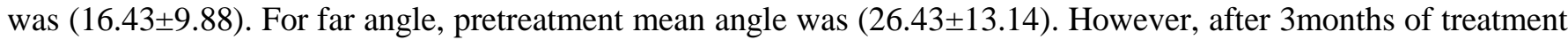
mean angle was (22.14 \pm 14.10$)$, after 6 months of treatment mean angle was (18.57 \pm 13.14$)$. and after 12 months of treatment mean was $(21.43 \pm 13.14)$. There is significant in near and far control after PTO therapy. 


\section{Example:}

A nine years old boy with cycloplegic refraction :OD: 0.75/-1.00 Axis75, OS: -2.00/-1.50 Axis 110 treated with alternating PTO and angle was measured before,during and after treatment and pictures as below
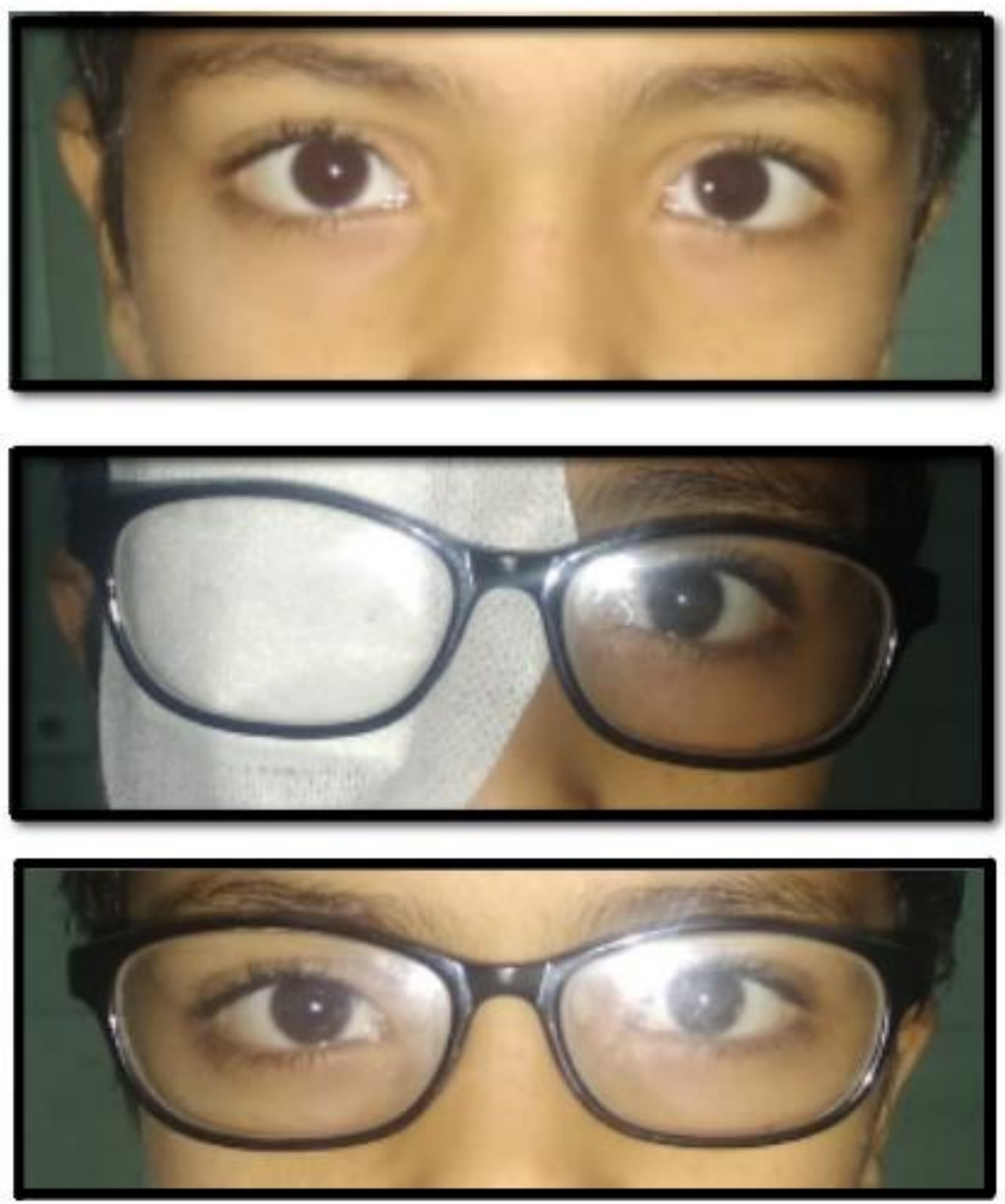

Figure (8) : shows Nsc 20 PD with fair control ,Dsc 25 PD with fair control

Figure (9): shows PTO of the dominant eye (OD)

Figure (10) : shows orthophoric for near and far with good control after 12 months.

Table (5): Success rate for convergence exercise, overminus, PTO and surgery.

\begin{tabular}{|c|c|c|c|c|c|c|}
\hline \multirow{2}{*}{$\begin{array}{l}\text { Follow up after } 12 \\
\text { months }\end{array}$} & \multicolumn{4}{|c|}{ Subgroup } & \multirow{2}{*}{ Total } & \multirow{2}{*}{\begin{tabular}{|c} 
P value \\
(Fisher's Exact \\
test)
\end{tabular}} \\
\hline & Convergence & Overminus & PTO & Surgery & & \\
\hline Under corrected & $4(66.67 \%)$ & $1(14 \%)$ & $4(57 \%)$ & $4(20 \%)$ & 13 & \multirow{4}{*}{$0.111^{*}$} \\
\hline Over corrected & 0 & 0 & 0 & $1(5 \%)$ & 1 & \\
\hline Ortho & $2(33.33 \%)$ & $6(86 \%)$ & $3(43 \%)$ & $15(75 \%)$ & 26 & \\
\hline Total & 6 & 7 & 7 & 20 & 40 & \\
\hline
\end{tabular}

Table (5): shows the follow up after 12 months in four subgroups. In convergence group there are 4 undercorrected, and 2 ortho. In overminus there are 1 undercorrected, and 6 ortho. In PTO group there are 4 undercorrected, and 3 ortho. In surgery there are 4 undercorrected, 1 overcorrected and 15 ortho .No significant statistical difference is detected between two groups as regards follow up. 


\section{DISCUSSION}

In non-surgical group, the success rate was $55 \%$ $(11 / 20)$. There were few reported retrospective articles studying the effectiveness of overminus treatment ${ }^{(9,10)}$. Alkhamous and Ahmed assessed the effectiveness of overminus lens therapy in a prospective study, without a control group ${ }^{(11)}$. The overmuines method the success rate was $86 \%(6 / 7)$ of patients at the 12 months of treatment, and deterioration rate was $14 \%(1 / 7)$ as in Huseyin et al. study, the success rate was $84 \%$ of patients who underwent a treatment with overminus spectacles. Those patients who demonstrated minimal control of (IXT) did not reveal any qualitative or quantitative improvement while wearing their overminus lenses. The number of patients was different in both studies ( 7 in our current study vs. 19 in Huseyin et al. study). However Huseyin et al study was retrospective one with longer duration of follow up 18 months ${ }^{(12)}$.

In Watts et al. ${ }^{(9)}$ the success rate was $72 \%$ of patients who underwent a treatment with overminus spectacles. The difference could be attributed to the following factors: first, the number of patients was different in both studies ( 7 in our current study vs. 20 in watts et al. study). Second, The age of patient as they included a wider range of age (Watts el al. included patients from 2 to 17 years and in this study, patients included were from 4 to 15 years of age). Third, the treatment period was different in both studies (12 months in our study vs. 6 months in watts et al. study).

Rowe et al. (10) results showed a 33\% deterioration rate on the long-term follow-up and that surgery was indicated in the patients who deteriorated in their control of exodeviation. The amount of overminus glasses was the same in both studies. So, the difference could be attributed to the following factors: First, the different number of patients in the two studies (21 patients in Rowe et al. study vs 7 patients in our study). Second, the longer follow-up period which was 5 years in Rowe et al. study compared to 12 months with treatment in the current study. That may explain the higher percentage of deterioration in the long-term follow-up in his study.

Other several retrospective studies have reported the effectiveness of PTO treatment for (IXT) ${ }^{(\mathbf{1 3}, 14)}$. In PTO method the success rate was $43 \%$ (3/7) of patient during 12 months of treatment and the deterioration rate was $57 \%(4 / 7)$.In comparison to our study, the rate of deterioration according to the PEDIG 2015, 6 months after PTO therapy was $2.2 \%$ in children from 12 to 35 months of age which is a younger age group than ours (15).

In another study for the PEDIG, the deterioration rate was only $0.6 \%$ in children from 3 to 10 years of age (16). The difference between our results and the PEDIG studies may be attributed to different the small sample size in our study which was 7 patients in the PTO group, in comparison with 90 patients in PEDIG study ${ }^{(15)}$, and 159 patients in the other one ${ }^{(16)}$.

The mean distance angle of the (IXT) in this study in the overminus group improved from baseline 21.29 PD to $2.14 \mathrm{PD}$ at the 12 months of treatment. When comparing these results with the PEDIG study at the 8th week of treatment, it improved from 18PD to 12.8 PD ${ }^{(17)}$.

Both studies prove the effectiveness of overminus treatment in improving the mean angle of (IXT). The difference in the mean angle of (IXT) may be explained by the shorter follow-up in PEDIG study which was 8 weeks in the PEDIG study (vs. 12 months in this study). Thus, it wasn't a sufficient treatment period for the treatment to be effective ${ }^{(\mathbf{1 7})}$.

The significant improvement was similar according to Watts et al. study in the overminus treatment; as the mean pretreatment angle of (IXT) was 28.5PD and the mean post-treatment angle of (IXT) was $18.3 \mathrm{PD}^{(9)}$.

In the current study, the mean distance and near angles of (IXT) in the PTO therapy group didn't show significant improvement at the 12 months, Alkhamous and Ahmed proved that PTO therapy can improve the deviation control but doesn't improve nor worsen the angle of deviation ${ }^{(\mathbf{1 1})}$.

The PEDIG noticed also no improvement in the angle of deviation despite improvement in the control which was consistent with the current study and thus proved that there wasn't a sufficient evidence to prescribe PTO for (IXT) ${ }^{(\mathbf{1 5})}$.

In this study, the mean distance angle of (IXT) in the PTO group improved from 26.43 PD to $21.43 \mathrm{PD}$ at the 12 months. On the other hand, the mean angle in the PEDIG study in the PTO improved from 27.1PD to 24.9 PD in the 6th months. As for the mean near angle of (IXT) in this study at the 12 months, it improved from 23.75 PD to $16.43 \mathrm{PD}$ at 12 months of treatment. In comparison to our study, the near angle of (IXT) improved in the PEDIG study from 19.4 PD baseline to 17.0 PD in the $6^{\text {th }}$ of treatment, which is different due to small sample size in our study which was 7 patients in PTO group, in comparison with 90 patients in PEDIG study ${ }^{(15)}$ and 159 patients in the other one ${ }^{(16)}$.

In this study, the mean near angle of (IXT) in the convergence exercise group improved from 26.83 PD to 15.0 PD at the 12 months. As for the mean distance angle of (IXT) in this study at the 12 months, it improved from 20.167 PD to 14.167 PD at 12 months of treatment which have low success rate than the other methods of treatment due to poorly compliant with convergence exercise.

In the Surgical group (BLR) our surgical success rate was $75.00 \%$, similar to other studies ${ }^{(7,18)}$. Vanessa stated that the range of success rate is $52 \%-69 \%{ }^{\left({ }^{(19)}\right.}$. In different studies, the success rate using BLR varied from $43 \%$ to $83 \%{ }^{(\mathbf{2 0}, \mathbf{2 1})}$. 
In addition, our results were different to the study by Jeoung and coworkers where 28 of 58 patients (48.3\%) had a satisfactory outcome in their BLR group. This difference could be attributed to the larger number of patients enrolled in their study ${ }^{(22)}$.

In our study we considered orthotropia \pm 10 PD, as the criterion for assessing surgical success after 12 months postoperative. However, this criterion, in other studies, may be considered valid only for surgeries with cosmetic purposes. The main purpose of surgery for the correction of exotropia is to obtain stable binocular vision. Taking this into consideration, well compensated orthophoria or $\mathrm{X}$ or esophoria were considered to be surgical success in their study, after minimum follow-up of 1 post-operative year ${ }^{(\mathbf{1 8})}$.

In our study, overcorrection represented 1 patient $(5 \%)$ in BLR. This was less thanthat in the study done by Lee and Lee where $3(6 \%)$ patients presented overcorrection after 1 year of follow-up, observed that of the 46 patients submitted to BLR ${ }^{(18)}$. This was also close to the study done by Jeoung and coworkers where there were no cases of overcorrection in their BLR group (22). However, in the study by Spierer and coworkers, in the BLR group, there were three cases of overcorrection $(11 \%)^{(23)}$. On the other hand, this was less than the study done by Fiorelli and coworkers ${ }^{(\mathbf{1 9})}$. These differences could be attributed to the difference in number of total patients in their study and ours.

In our study, incomittance was defined as a change of more than 5 PD from primary to lateral gaze. We found no lareral incomittance in any of our patients or the presence of face turn. Oh and Hwang considered lateral incomitance to be an important factor of persistent overcorrection. Some authors disagree and believe that, although a certain ET to lateroversion may remain after surgery, it generally tends to reduce over the course of time. For this reason, Oh and Hwang planned these surgeries, based on the magnitude of the deviation for distant fixation in primary position. Postoperative large angle ET, being desirable for longterm prevention of recurrence, may cause a monofixation syndrome with loss of stereopsis and increase the risk of needing to intervene for a nonresolving ET ${ }^{(24)}$.

This concern was ruled out in some studies Nelson and Wagner ${ }^{(25)}$ whereas in others, it was verified only when the lateral rectus muscle was recessed by more than 8 to $9 \mathrm{~mm}{ }^{(26)}$. However, in another study it was reported that 15 had an initial overcorrection of $20 \mathrm{PD}$ or more after surgery for exodeviation which was reduced to $10 \mathrm{PD}$ or less at distance and at near within a postoperative 4 weeks in most patients and that reoperation for consecutive ET was necessary in only $5.9 \%$ of the patients ${ }^{(27)}$.

\section{CONCLUSION}

It could be concluded that surgical method has more effect in treatment of (IXT) than non-surgical methods but the non-surgical method is more important in younger children. The overmius glasses is more effective in treatment of (IXT) than the other nonsurgical method due to poor compliance among children in PTO and Convergence exercise therapy. A larger trial for a longer duration is warranted to assess the effectiveness of different modalities of treatment of (IXT).

\section{REFERENCES}

1. Mohney BG, Burke JP, Govindan M et al. (2005): Incidence and types of childhood exotropia:a populationbased study. Ophthalmology, 112: 104-108.

2. Nusz K, Clarke M and Ekdawi N (2009): Post-operative outcomes in children with intermittent exotropia from a populationbased. Cohort J AAPOS., 13: 4-7.

3. Wright KW (2008): Exotropia. In: Wright $\mathrm{KW}$ (ed). Color atlas of Strabismus surgery: Strategies and Techniques, third edition, Springer Science \pm Business Media, Inc., LCC, NY10013, USA, Pp. 42-51.

4. Gürlü VP, Erda N (2008): Diagnostic occlusion test in intermittent exotropia. J AAPOS., 12:504-6.

5. Hutchinson AK (2001): Intermittent exotropia. Ophthalmic Clin North Am., 14(3):399-406.

6. Von Noorden GK, Campus EC (2002): Principles of surgical treatment.In: Lampert R, Cox K, Burke D (Eds.). Binocular vision and ocular motility:theory and management of strabismus, 6th edition, Mosby, Inc.,St.Louis, Missuri 63146, UA, Pp. 59-64.

7. Gnanaraj L, Richardson SR (2005): Interventions for intermittent distance exotropia. Eye, 19:617-21.

8. Kubota N, Maruo T, Sakaue T et al. (2001): Intermittent exotropia surgery in children: Long term outcome regarding changes in binocular alignment. A study of 666 cases. Binocul Vis Strabismus Q., 16:265-70.

9. Watts $P$, Tippings $E$ and Al-Madfai $H$ (2005): Intermittent Exotropia, Overcorrecting Minus Lenses, and the New Castle scoring system. J AAPOS., 9:460-4.

10. Rowe FJ, Noonan CP, Freeman G et al. (2009): Intervention for intermittent distance exotropia with overcorrecting minus lenses. Eye, 23:320-5.

11.AlKhamous LS, Ahmed AA (2016): Does occlusion therapy improve control in intermittent exotropia? SJOPT., 433:1-4.

12.Huseyin B, Ayse GY, Unsal S et al. (2016): Overcorrecting minus lens therapy in patients with intermittent exotropia. Int Ophthalmol., 36:1-6.

13. Berg PH, Isenberg SJ (1991): Treatment of unilateral exotropia by part-time occlusion. Am Orthopt J., 41:72-6.

14. Suh YW, Kim SH, Lee JY et al. (2006): Conversion of intermittent exotropia types subsequent to part-time Occlusion therapy. Graefes Arch Clin Exp Ophthalmol., 244: 705-8.

15.Pediatric Eye Disease Investigator Group (2015): A randomized trial comparing Part-time Patching with Observation for Intermittent Exotropia in Children 12 to 35 Months of age. Am J Ophthalmol., 122:1718-25.

16.Pediatric Eye Disease Investigator Group (2014): A randomized trial comparing part-time patching with observation for children 3 to 10 years of age with intermittent exotropia. Am J Ophthalmol., 121: 2299-310.

17.Pediatric Eye Disease Investigator Group (2016): A 
randomized trial evaluating short-term effectiveness of Overminus Lenses in Children 3 to 6 Years of Age with Intermittent Exotropia. Am J Ophthalmol., 123:2127-36.

18. Lee S, Lee YC (2001): Relationship between motor alignment at postoperative day 1 and at year 1 after symmetric and asymmetric surgery in intermittent exotropia. Jpn J Ophthalmol., 45(2):167-71.

19. Fiorelli VM, Goldchmit M, Uesugui CF et al. (2007): Intermittent exotropia: comparative surgical results of lateral recti-recession and monocular recess-resect. Arq Bras Oftalmol., 70(3):429-32.

20. Chia A, Seenyen $L$ and Long QB (2006): Surgical experiences with two-muscle surgery for the treatment of intermittent exotropia. J AAPOS.,10(3):206- 11.

21.Ekdawi NS, Nusz KJ, Diehl NN, Mohney BG (2009): Postoperative outcomes in children with intermittent exotropia from a population-based cohort. J AAPOS., 13(1):4-7.

22.Jeoung JW1, Lee MJ and Hwang JM (2006): Blateral lateral rectus recession versus unilateral recess-resect procedure for exotropia with a dominant eye. Am J Ophthalmol.,141(4):683-8

23.Spierer O, Spierer A, Glovinsky J et al. (2010): Moderate-Angle Exotropia: A Comparison of Unilateral and Bilateral Rectus Muscle Recession, Ophthalmic Surg Lasers Imaging, 41:355- 9.

24. Oh J Y, Hwang JM (2006): Survival analysis of 365 patients with exotropia after surgery. Eye, 20: 1268-72.

25. Nelson LB, Wagner RS (1998): Unilateral vs bilateral strabismus surgery for exotropia. J Pediatr Ophthalmol Strabismus, 35: 132-138.

26. Dadeya S, Kamlesh A (2003): Long-term results of unilateral lateral rectus recession in intermittent exotropia. J Pediatr Ophthalmol Strabismus, 40:283-7.

27.Kim T, Kim JH and Hwang JM (2005): Long term outcome of patients with large overcorrection following surgery for exotropia. Ophthalmologica., 219:237-42. 